NASA-TM-112144

\title{
Freezing behavior of stratospheric sulfate aerosols inferred from trajectory studies
}

\author{
A. Tabazadeh and O. B. Toon \\ NASA Ames Research Center, Moffett Field, California
}

Patrick Hamill

Department of Physics, San Jose State University, San Jose, California

\begin{abstract}
Temperature histories based on 10-day back trajectories for six ER-2 flights during AASE I (1989) and AAOE (1987) are presented. These trajectories along with the properties of the observed PSC (polar stratospheric cloud) particles are used here to infer the physical state of the preexisting sulfuric acid aerosols. Of all the ER-2 flights described here, only the PSCs observed on the flights of January 24 and 25,1989 are consistent with the thermodynamics of liquid ternary solutions of $\mathrm{H}_{2} \mathrm{SO}_{4} / \mathrm{HNO}_{3} / \mathrm{H}_{2} \mathrm{O}$ (Type Ib PSCs). For these two days, back trajectories indicate that the air mass was exposed to SAT (sulfuric acid tetrahydrate) melting temperatures about 24 hours prior to being sampled by the ER-2. For the remaining ER-2 flights (January, 16, 19. and 20 for the AASE I campaign and August 17 for the AAOE campaign), the observed PSCs were probably composed of amorphous solid solutions of $\mathrm{HNO}_{3}$ and $\mathrm{H}_{2} \mathrm{O}$ (Type Ic PSCs). Formation of such Type Ic PSCs requires the presence of solid $\mathrm{H}_{2} \mathrm{SO}_{4}$ aerosols since liquid aerosols yield ternary solutions. The 10-day back trajectories of these flights indicate that the air mass was not exposed to SAT melting temperatures during the past week and had experienced cooling/warming cycles prior to being sampled by the ER-2. These temperature histories, recent laboratory measurements and the properties of glassy solids suggest that stratospheric $\mathrm{H}_{2} \mathrm{SO}_{4}$ aerosols may undergo a phase transition to SAT upon warming at $\sim 198 \mathrm{~K}$ after going through a cooling cycle to about $194 \mathrm{~K}$ or lower.
\end{abstract}

\section{Introduction}

It is believed that stratospheric sulfate aerosols serve as condensation nuclei for the formation of Type I PSCs $\left(\mathrm{HNO}_{3}\right.$ containing aerosols). Depending on the physical state of the pre-existing sulfate aerosols, different classes of Type I PSCs may form [Browell et al., 1990; Toon et al., 1990; Tabazadeh and Toon, 1995]. We have recently shown that if the preexisting $\mathrm{H}_{2} \mathrm{SO}_{4} / \mathrm{H} 2 \mathrm{O}$ aerosols are liquid then temary solutions of $\mathrm{H}_{2} \mathrm{SO}_{4} / \mathrm{HNO}_{3} / \mathrm{H}_{2} \mathrm{O}$ (Type Ib) will form (Tabazadeh et al., 1994a]. However, if the $\mathrm{H}_{2} \mathrm{SO}_{4} / \mathrm{H}_{2} \mathrm{O}$ aerosols are frozen, an amorphous solid solution of $\mathrm{HNO}_{3}$ and $\mathrm{H}_{2} \mathrm{O}$ (Type Ic) will initially form [Tabazadeh and Toon, 1995]. In this paper, we use temperature histories and the thermodynamic properties of the $\mathrm{H}_{2} \mathrm{SO}_{4} / \mathrm{H}_{2} \mathrm{O}$ system to describe a new mechanism for the formation of solid phase stratospheric sulfate aerosols.

Jenson et al. [1991] and Luo et al. [1994] have suggested that $\mathrm{H}_{2} \mathrm{SO}_{4}$ aerosols may freeze when ice homogeneously nucleates in a supercooled $\mathrm{H}_{2} \mathrm{SO}_{4} / \mathrm{H}_{2} \mathrm{O}$ solution. However, it is not clear whether ice nucleation in solution leads to the freczing of $\mathrm{H}_{2} \mathrm{SO}_{4}$ in the solution as SAT. Due to the rapid

Copyright 1995 by the American Geophysical Union.

Paper number 95GL01335

0094-8534/95/95GL-01335\$03.00 growth of ice crystals, the $\mathrm{H}_{2} \mathrm{SO}_{4}$ may be incorporated as an impurity in the ice lattice rather than aggregating with water in solution to form SAT. Also, Luo et al. [1994] have argued that if $\mathrm{H}_{2} \mathrm{SO}_{4}$ aerosols contain an appropriate heterogeneous core, then the freezing of the aerosols into SAT may occur at temperatures above the ice frost point. However, for the ER-2 flight of January 24,1989 where the observed cloud particles were ternary solutions, the aerosols remained supercooled even for temperatures below the ice frost point [Tabazadeh et al., 1994a, Drdla et al., 1994]. This may indicate that $\mathrm{H}_{2} \mathrm{SO}_{4}$ aerosols do not freeze above the ice frost point in agreement with the earlier calculations of Jenson et al. [1991].

Recently, Iraci et al. [1994] have proposed that $\mathrm{H}_{2} \mathrm{SO}_{4}$ aerosols may freeze upon warming in the stratosphere. They observed that $\mathrm{H}_{2} \mathrm{SO}_{4} / \mathrm{H}_{2} \mathrm{O}$ solutions exposed to $\mathrm{HNO}_{3}$ vapor and cooled to $\sim 191.5 \mathrm{~K}$ remained liquid at temperatures above the ice frost point. However, such solutions froze to SAT upon warming at $\sim 198 \mathrm{~K}$. Crystallization of $\mathrm{H}_{2} \mathrm{SO}_{4} / \mathrm{H}_{2} \mathrm{O}$ supercooled solutions into SAT upon warming is very similar to the devitrification (glass $\rightarrow$ crystal) process, a commonly observed behavior of glassy solids. If a glassy solid is heated to temperatures above the glass transition temperature, it coverts to either a pure crystal or a mixture of crystalline phases [R awson, 1991]. As described below, the glass transition temperature for $\mathrm{H}_{2} \mathrm{SO}_{4} / \mathrm{H}_{2} \mathrm{O}$ solutions is $<165 \mathrm{~K}$. Hence, $\mathrm{H}_{2} \mathrm{SO}_{4} / \mathrm{H}_{2} \mathrm{O}$ solutions probably do not form glasses upon cooling in the stratosphere. However, using the properties of glass forming solutions, we suggest that it may be possible for $\mathrm{H}_{2} \mathrm{SO}_{4} / \mathrm{H}_{2} \mathrm{O}$ solutions to behave as glassy solids and therefore crystallize upon warming to form SAT.

\section{$\mathrm{H}_{2} \mathrm{SO}_{4} / \mathrm{H}_{2} \mathrm{O}$ Supercooled and Glassy Solutions}

Numerous laboratory observations indicate that it is difficult to freeze $\mathrm{H}_{2} \mathrm{SO}_{4} / \mathrm{H}_{2} \mathrm{O}$ solutions into crystalline phases of $\mathrm{H}_{2} \mathrm{SO}_{4}$ and $\mathrm{H}_{2} \mathrm{O}$ upon cooling a binary solution [e.g., Gable, 1950; Vuillard, 1957; Middlebrook et al., 1993; Zhang et al., 1993]. For example, Vuillard [1957] was able to cool $\mathrm{H}_{2} \mathrm{SO}_{4} / \mathrm{H}_{2} \mathrm{O}$ bulk solutions $\left(\mathrm{H}_{2} \mathrm{SO}_{4}\right.$ acid weight percent $\left.>37\right)$ to temperatures below $180 \mathrm{~K}$ without crystallization. Also, for $\mathrm{T}$ $<180 \mathrm{~K}, \mathrm{H}_{2} \mathrm{SO}_{4} / \mathrm{H}_{2} \mathrm{O}$ supercooled solutions formed glasses instead of the crystalline phases [Vuillard, 1957]. Glassy solids are usually formed because the nucleation rate for crystal formation is too low, or, if the nucleation rate is large, the rate of the growth of the nuclei is small [e.g, Ruckenstein and $/ \mathrm{hm}$, 1976; Rawson, 1991]. The rate of growth is limited by the diffusion of the $\mathrm{H}_{2} \mathrm{SO}_{4}$ and $\mathrm{H}_{2} \mathrm{O}$ molecules in a supercooled solution, which is related to the viscosity of the $\mathrm{H}_{2} \mathrm{SO}_{4} / \mathrm{H}_{2} \mathrm{O}$ solution.

The glass transition temperature of a supercooled solution is defined as that temperature at which the viscosity of the solution becomes $10^{14.6} A$, where $A$ (poise) is a parameter in the viscosity equation [e.g., Ruckenstein and $\mathrm{Ihm}, 1976]$. We have used this expression to calculate the glass transition 
temperature for $\mathrm{H}_{2} \mathrm{SO}_{4} / \mathrm{H}_{2} \mathrm{O}$ supercooled solutions using the viscosity parameters given by Williams and Long [1994]. The calculated glass transition temperature for $\mathrm{H}_{2} \mathrm{SO}_{4} / \mathrm{H}_{2} \mathrm{O}$ solutions, containing less than $60 \% \mathrm{H}_{2} \mathrm{SO}_{4}$ by weight, varies from 150 to $165 \mathrm{~K}$, depending on the solution composition. This agrees with the glass transition temperatures measured by Vuillard [1957]. Therefore, at stratospheric temperatures $\mathrm{H}_{2} \mathrm{SO}_{4}$ aerosols which do not freeze remain supercooled instead of transforming into glass.

The viscosity of supercooled $\mathrm{H}_{2} \mathrm{SO}_{4} / \mathrm{H}_{2} \mathrm{O}$ solutions increases rapidly with temperature decrease. For example, cooling a $\mathrm{H}_{2} \mathrm{SO}_{4} / \mathrm{H}_{2} \mathrm{O}$ solution $\left(60 \% \mathrm{H}_{2} \mathrm{SO}_{4}\right.$ by weight) from $200 \mathrm{~K}$ to $190 \mathrm{~K}$ increases the viscosity of the solution by an order of magnitude [Williams and Long, 1994]. Even though cooling a solution increases the nucleation rate of the crystalline embryos, the increase in the viscosity of the solution may prevent the growth of the embryos. The glass forming ability of $\mathrm{H}_{2} \mathrm{SO}_{4} / \mathrm{H}_{2} \mathrm{O}$ solutions indicates that it may be difficult for crystal embryos nucleated in a solution to grow due to the high viscosity of the supercooled solution. If a supercooled solution, containing crystalline embryos transforms into a glassy state, then the embryos will freeze in position and may never grow into a crystal phase.

As indicated above, Iraci et al. [1994] have observed that $\mathrm{H}_{2} \mathrm{SO}_{4} / \mathrm{H}_{2} \mathrm{O}$ solutions froze upon warming at $\sim 198 \mathrm{~K}$ to form either SAT or SAH (sulfuric acid hemihexahydrate). First, the $\mathrm{H}_{2} \mathrm{SO}_{4} / \mathrm{H}_{2} \mathrm{O}\left(54 \% \mathrm{H}_{2} \mathrm{SO}_{4}\right.$ by weight) solution was cooled to $191.5 \mathrm{~K}$ and then the cold film was exposed to $2.3 \times 10^{-6}$ torr of $\mathrm{HNO}_{3}$ vapor for about 9 minutes. The film was then warmed at $1 \mathrm{~K}$ per minute in the presence of $\mathrm{HNO}_{3}$ vapor. Most films crystallized at $\sim 196.5 \mathrm{~K}$ to $\mathrm{SAH}$, which then converted to SAT at $~ 198 \mathrm{~K}$. The likely explanation for the freezing of the supercooled solutions upon warming is that crystalline embryos were nucleated at the colder temperatures in the solution. Upon warming, the viscosity of the solution was decreased, allowing the existing crystalline embryos to grow. Also, it is known that addition of small amounts of a ternary component to a binary glassy solid causes the glass to devitrify much more rapidly [Rawson, 1991]. For example, even trace amount of salts left by the fingers on a freshly prepared glass surface will cause local devitrification. Thus, the addition of a ternary component to a glass system increases the probability of the crystal nuclei formation. Therefore, incorporation of $\mathrm{HNO}_{3}$ into a $\mathrm{H}_{2} \mathrm{SO}_{4} / \mathrm{H}_{2} \mathrm{O}$ film may increase the number of crystalline embryos formed in the solution at the colder temperatures and therefore influence the crystallization of the supercooled solution upon warming.

More laboratory work is needed to see whether the uptake of $\mathrm{HNO}_{3}$ by the supercooled $\mathrm{H}_{2} \mathrm{SO}_{4} / \mathrm{H}_{2} \mathrm{O}$ solution is necessary for the freezing of $\mathrm{H}_{2} \mathrm{SO}_{4} / \mathrm{H}_{2} \mathrm{O}$ solutions upon warming. This can be carried out simply in the laboratory by cooling a $\mathrm{H}_{2} \mathrm{SO}_{4} / \mathrm{H}_{2} \mathrm{O}$ solution and then warming the solution both in the absence and the presence of $\mathrm{HNO}_{3}$ vapor. The presence of heterogeneous wall surfaces in the laboratory could also increase the probability of the crystal nuclei formation in the solution. Hence, it is not clear whether submicron $\mathrm{H}_{2} \mathrm{SO}_{4} / \mathrm{H}_{2} \mathrm{O}$ aerosols in the stratosphere behave in the same manner as the thin films studied in the laboratory [Iraci et al., 1994]. However, below we use air mass temperatures histories to show that $\mathrm{H}_{2} \mathrm{SO}_{4} / \mathrm{H}_{2} \mathrm{O}$ aerosols may crystallize upon warming in the stratosphere.

\section{Trajectory Analysis}

Figure 1 illustrates back trajectories for 6 ER-2 flights. The final points were taken along the ER-2 flight tracks and are given in Table 1. The temperatures obtained by the Goddard trajectory model do not exactly agree with the measured ER-2
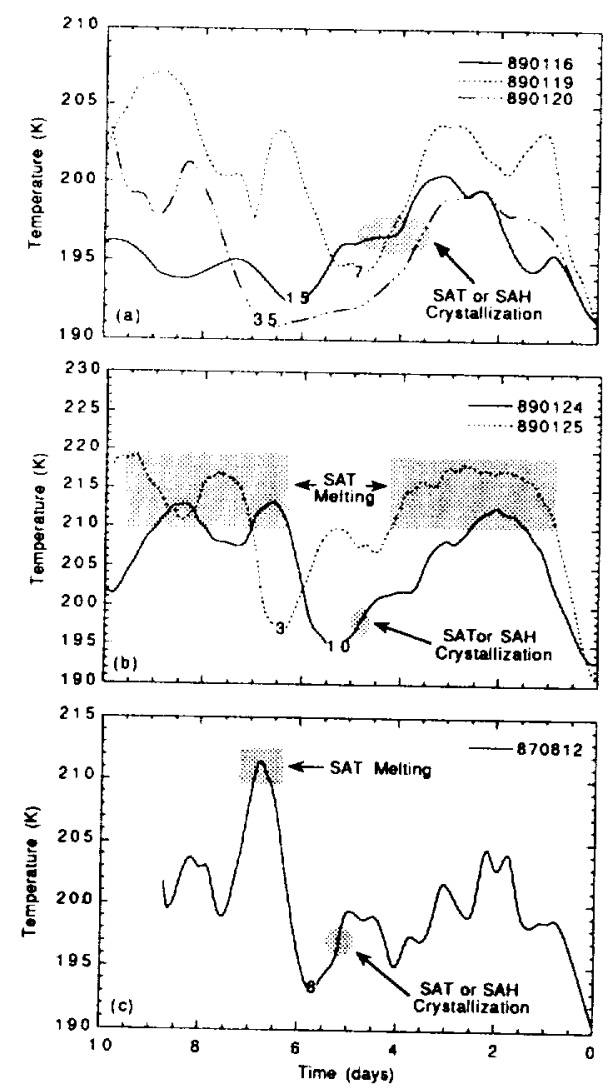

Figure 1. 10-day back trajectories for six ER-2 flights. The flight dates are indicated in the chart. The numbers on the solid lines indicate the weight percent of $\mathrm{HNO}_{3}$ present in a ternary solution of $\mathrm{H}_{2} \mathrm{SO}_{4} / \mathrm{HNO}_{3} / \mathrm{H}_{2} \mathrm{O}$ at the minimum of the temperature [Tabazadeh et al., 1994b]. The amount of $\mathrm{HNO}_{3}$ absorbed at colder temperatures may influence the crystallization rate of the SAT embryos in solution. SAT melting temperatures and crystallization regions of the supercooled solutions are marked in the figure. See text for more detail.

temperatures. Thus, the temperatures calculated by the back trajectories were adjusted (by adding or subtracting at most a couple of degrees) to match the measured ER-2 temperatures at the final point. The error in the temperatures calculated by the back trajectories should increase as one goes back in time. For all the flights shown in Figure 1, the SAT melting temperature was above $210 \mathrm{~K}$ based on the water vapor concentration [Zhang et al., 1993; Middlebrook et al., 1993; Kelly et al.,
1990].

Figure 2 illustrates the variation of the cloud particle volume with temperature for the flights of January 16, 20 and

Table 1. Conditions Used for the Back Trajectories

\begin{tabular}{lllll}
\hline Flight & Time (UT) & PT (K) & Latitude & Longitude \\
\hline $890: 16$ & 37270 & 445 & 72.42 & 16.11 \\
890119 & 41820 & 449 & 77.04 & 15.63 \\
890120 & 39750 & 443 & 77.50 & 16.00 \\
890124 & 38000 & 435 & 72.54 & 15.96 \\
890125 & 38700 & 441 & 73.68 & 18.24 \\
870817 & 62000 & 419 & -66.41 & -68.26 \\
\hline
\end{tabular}

Where UT is the universal time in seconds and PT is the potential temperature in kelvin. 

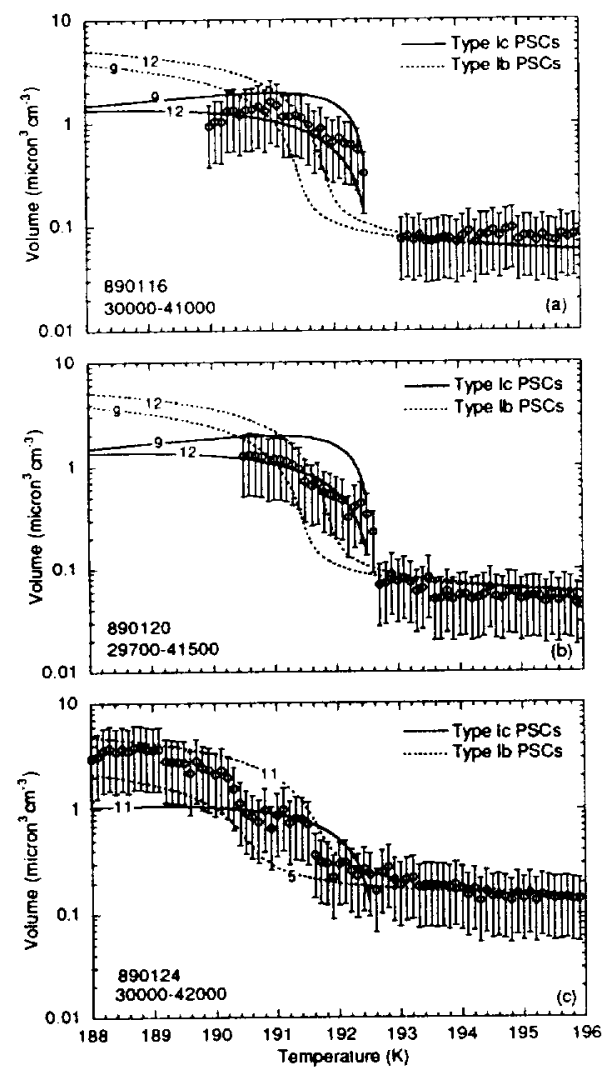

Figure 2. Variation of the cloud particle volume with temperature for the ER-2 flights of January 16, (panel (a)), January 20 (panel (b) and January 24 (panel (c)). The circles are calculated by averaging the FSSP-300 measurements of particle volume (particles $<2 \mu \mathrm{m}$ ) for every temperature and the uncertainties $( \pm 60 \%$ ) are indicated as error bars [Dye et al., 1992; Baumgardner et al., 1992]. The observation time for the measurements is given in UT seconds and is indicated in the chart. The numbers on the lines indicate the total $\mathrm{HNO}_{3}$ mixing ratio in units of ppbv, which corresponds to the variation of the $\mathrm{HNO}_{3}$ mixing ratio on these three days inferred form the $\mathrm{N}_{2} \mathrm{O}$ data (Fahey et al., 1989). For computations, the total pressure and the total $\mathrm{H}_{2} \mathrm{O}$ mixing ratio were set at $55 \mathrm{mb}$ and 5 ppmv, respectively. The solid lines and the dashed lines were calculated assuming that the observed cloud particles were composed of Type Ic and Type Ib particles, respectively [Tabazadeh and Toon, 1995, Tabazadeh et al., 1994b]. For all the calculations, the total $\mathrm{H}_{2} \mathrm{SO}_{4}$ mass present per cubic meler of air was set at $0.05 \mu \mathrm{g}$ for panels (a) and (b) and 0.10 $\mu \mathrm{g}$ for panel (b).

24,1989 . The denitrified regions of the flight track are excluded in Figure 2 [Dye et al., 1992]. On January 19 and 25 , NO was measured instead of $\mathrm{NO}_{y}$ and therefore it is not possible to locate the denitrified regions of the flight track [Kawa et al., 1992]. Thus similar analysis of volume versus temperature plots, as shown in Figure 2, are not reliable on January 19 and 25. On August 17, 1987, the archived FSSP. 300 measurements of particle volume are unrealistic and we used the particle composition data instead of the particle volume data, as described below.

The volume behavior observed on January 24 , which is similar to that of January 25, can be explained by the presence of ternary solutions (Type 1b) in the air mass [Dye et al., 1992; Tabazadeh et al., i594; Carslaw et al., 1994]. However, we have recently shown that the observed volumes on January 20 (also 16 and 19) are consistent with the presence of Type Ic PSC in the air mass [Tabazadeh and Toon, 1995; see also the discussions by Dye et al., 1992]. The reason for the difference in the slopes shown in Figures $2 a$ and $2 b$ compared to that of Figure $2 \mathrm{c}$ is that Type Ib and Type Ic particles follow different vapor pressure curves.

For the flight of August 17, 1987, the observed cloud composition at the point given in Table 1 is consistent with Type Ic PSC particles. At this point, the aerosols contain $\sim 3$ ppbv $\mathrm{HNO}_{3}$ at $190 \mathrm{~K}$ [Fahey et al., 1989; Kawa et al., 1992]. If Type Ia ( $\mathrm{HNO}_{3}$ tri- or dihydrate) or Type Ib PSCs were present in the air mass instead of Type Ic PSCs, then the $\mathrm{HNO}_{3}$ mixing ratio in the aerosol would have been $\sim 6.0 \mathrm{ppbv}$ and less than 1 ppbv, respectively [Worsnop et al., 1992; Tabazadeh et al., $1994 b]$.

On January 16, 19 and 20 (Figure 1a), the air mass was not exposed to SAT melting temperatures during the past 10 days. However, for all of these flights, the air mass underwent a cooling cycle, while staying above the ice frost point. Based on the arguments given in the previous section, we suggest that the aerosols may have crystallized upon warming at $\sim 196$ $-198 \mathrm{~K}$. This region is marked in Figure 1 as SAT or SAH crystallization. For example, in panel $1 \mathrm{a}$, temperatures became cold enough on days 5 through 7 to initiate nucleation of SAT (or SAH) embryos and SAT (or SAH) likely crystallized on day $4( \pm 1)$. After crystallization, temperatures remained below the SAT melting and amorphous solid solutions were observed after cooling to the PSC formation temperatures as inferred from Figures $1 \mathrm{a}$ and $1 \mathrm{~b}$. However, it could be argued that the aerosols might have been frozen when the coolings occurred on days 5 through 7 and therefore the subsequent warming on day $4( \pm 1)$ may have not caused the freezing of the aerosols. Also, it is possible that the freezing of the sulfate aerosols may have occurred during the cooling cycles shown in Figure 1a instead of the warming cycle marked in the figure.

The PSCs observed on January 24 and 25 were composed of ternary solutions as inferred from Figure 2c. Also, for these two days, the air mass was exposed to SAT melting temperatures before the final cooling occurred. These two observations are separately consistent with the pre-existing $\mathrm{H}_{2} \mathrm{SO}_{4} / \mathrm{H}_{2} \mathrm{O}$ aerosols being liquid prior to the formation of Type I PSCs at the locations given in Table 1 [Tabazadeh et al., 1994a; Carslaw et al., 1994]. In addition, on January 24, the cloud particles were liquid at other locations in the ER-2 flight track when the air temperature was below the ice frost point [Tabazadeh et al., 1994a; Drdla et al., 1994; Carslaw et al., 1994]. These observations strongly suggest that the freezing of the stratospheric sulfate aerosols does not occur during a cooling cycle, which we could not determine uniquely from the trajectories shown in Figure 1a.

If temary solutions remain liquid during a cooling cycle, as shown by the January 24 and 25 data, then the suggestion that the stratospheric sulfate aerosols may crystallize upon warming can now be inferred from the August 17. 1987 back trajectory (Figure 1c). On this day, the air mass was exposed to SAT melting temperatures approximately 1 week prior to being sampled by the ER-2 and therefore the aerosols were probably liquid on day 6 . If the aerosols were frozen on day 6 , then the PSCs observed on January 24 and 25 should have also been frozen. After the SAT melting episode (day 7) and the cooling cycle (day 6 ) the air mass then warmed to about $205 \mathrm{~K}$ (day 2 ) before cooling $(\sim 190 \mathrm{~K})$ to the point where the cloud particles were sampled by the ER-2. As indicated above, the observed cloud composition on the August 17 flight appear to be of Type Ic PSCs. Hence, the warming cycle marked in Figure if may have caused the $\mathrm{H}_{2} \mathrm{SO}_{4}$ aerosols to freeze because if the $\mathrm{H}_{2} \mathrm{SO}_{4}$ aerosols were liquid, then ternary solutions would have formed. Since this behavior has been observed in the 
laboratory [Iraci et al., 1994], we suggest that cooling followed by warming is responsible for the freezing of the stratospheric sulfate aerosols.

\section{Discussion}

Based on the trajectory analysis presented in this paper, a new mechanism was described for the freezing of the stratospheric sulfate aerosols. This mechanism requires, as an initial step, the cooling of a $\mathrm{H}_{2} \mathrm{SO}_{4} / \mathrm{H}_{2} \mathrm{O}$ aerosol to low temperatures. If a cooling cycle is then followed up by a warming to $\sim 196-198 \mathrm{~K}$, then the aerosols may freeze due to the growth of the crystalline embryos formed at the colder temperatures. A minimum temperature of at least $194 \mathrm{~K}$ is required for the cooling cycle based on the August 17, 1987 air mass temperature history. However, more laboratory work is needed to determine both this minimum temperature and the role of the $\mathrm{HNO}_{3}$ uptake by the supercooled solutions. The $\mathrm{HNO}_{3}$ absorbed at colder temperature may increase the nucleation rate of the crystalline embryos and therefore influence the crystallization of the supercooled aerosols upon warming.

In general, stratospheric sulfate aerosols should be frozen under winter polar stratospheric conditions because cooling/warming cycles will most likely initiate the freezing of the aerosols. If a 10-day back trajectory of an air mass has not passed through a SAT melting temperature, then the observed PSCs should be of Type Ic (January 16, 19 and 20). However, if the 10-day back trajectory of an air mass has experienced a SAT melting temperature, then temary solutions will form on the first cooling cycle (January 24 and 25). If ice does not freeze from a temary solution in the first cooling cycle, then upon warming, the sulfate aerosols will probably freeze at $-198 \mathrm{~K}$. The subsequent cooling cycles following the first should result in the formation of Type Ic particles (August 17, 1987). Outside the polar vortex, the average temperatures are usually higher relative to the temperatures inside the vortex and therefore ternary solutions may form routinely at the edges of the polar vortex. However, inside the polar vortex, especially in the Antarctic, once the sulfate aerosols freeze, the average temperatures rarely exceed SAT melting temperatures. Therefore, most of the PSC sightings inside the polar vortex should be either of Type Ic or any of the crystalline phases of $\mathrm{HNO}_{3}$ and $\mathrm{H}_{2} \mathrm{O}$, such as NAT or NAD (nitric acid dihydrate).

We plan to extend the trajectory analysis described here to gain more insight into the mechanisms that are involved in the formation of the crystalline phases of $\mathrm{HNO}_{3}$ and $\mathrm{H}_{2} \mathrm{O}$ in the stratosphere. We speculate that the formation of such phases may also involve cooling/warming cycles. In a cooling cycle, depending on the physical state of the sulfate aerosols, either temary solutions or $\mathrm{HNO}_{3} / \mathrm{H}_{2} \mathrm{O}$ amorphous solid solutions will initially form in the air mass. During the subsequent warming, the crystalline phases (NAT or NAD) may nucleate either from the ternary or the amorphous solid solutions.

Acknowledgments. We thank J. Dye, E. Jenson, and M. Tolbert for helpful discussions. We are also grateful to $L$. Lait and $P$. Newman for providing us with an input file to run the Goddard trajectory model. This research was completed while A. Tabazadeh held an NRC/NASA Postdoctoral Fellowship.

\section{References}

Browell, E. V., et al., Airborne lidar observations in the wintertime Arctic stratosphere: Polar stratospheric clouds, Geophys. Res. Lell., $17,385,1990$.

Baumgardner, D., et al., Interpretation of measurements made by the forward scaltering spectrometer probe (FSSP-300) during the airborne Arctic stratospheric expedition, J. Geophys. Res., 30, 8035, 1992.

Carslaw, K. S., et al., Stratospheric aerosol growth and $\mathrm{HNO}_{3}$ gas phase depletion from coupled $\mathrm{HNO}_{3}$ and water uptake by liquid particles, Geophys. Res. lett., 21, 2479, 1994.

Drdla, K., et al., Analysis of the physical state of one Arctic polar stratospheric cloud based on observations, Geophys. Res. Lett., 21, 2475, 1994

Dye, J. E., et al., Panicle size distribution in Arctic polar stratospheric clouds, growth and freezing of sulfuric acid droplets, and implications for cloud formation, J. Geophys. Res., 30, 8015, 1992.

Fahey, D. W., et al., In situ measurements of the total reactive nitrogen, total water, and aerosol in a polar stratospheric cloud in the Antarctic, J. Geophys. Res., 94, 11,299, 1989.

Gable, C. M., et al., Phase equilibria of the system sulfur trioxide-water, J. Am. Chem. Soc., 72, 1445, 1950.

Iraci, L. T., et al., Growth of nitric acid hydrates on thin sulfuric acid films, Geophys. Res. Letl., 21, 867, 1994.

Jenson, E. J., et al., Homogenous freezing nucleation of the stratospheric solution droplets, Geophys. Res. Lett., 18, 1857, 1991.

Kawa, S. R., et al., The Arctic polar stratospheric cloud aerosol: Aircraft measurements of reactive nitrogen, total water, and particles, J. Geophys. Res., 97, 7925, 1992.

Kelly, K. K., et al., A comparison of the ER-2 measurements of stratospheric water vapor between the 1987 Antarctic and the 1989 Arctic airbome missions, Geophys. Res. Lett., 17, 465, 1990.

Luo, B., et al., Freezing of stratospheric aerosol droplets, Geophys. Res. Lett., 17, 465, 1994.

Middlebrook, A. M., et al., Fourier Transform-Infrared studies of thin $\mathrm{H}_{2} \mathrm{SO}_{4} / \mathrm{H}_{2} \mathrm{O}$ films: Formation, water uptake, and solid-liquid phase changes, J. Geophys. Res., 98, 20,473, 1993.

Rawson., H., Glasses and Their Applications, Institute of Metals, London, 1991.

Ruckenstein, E., and S. K. Ihm, Kinetics of Glass Formation, J. Chem. Soc. Faraday Trans. I., 72, 764, 1976.

Tabazadeh, A., et al., A study of Type I polar stratospheric cloud formation, Geophys. Res. Lett., 21, 1619, 1994a.

Tabazadeh, A., et al., A model for studying the composition and chemical effects of stratospheric aerosols, J. Geophys. Res., 99. $12,897,1994 \mathrm{~b}$.

Tabazadeh, A. and O. B. Toon, The presence of $\mathrm{HNO}_{3} / \mathrm{H}_{2} \mathrm{O}$ amoprhous solid solutions with a variable composition in the stratosphere, $J$. Geophys. Res., in press.

Toon, O. B., et al., An analysis of lidar observations of polar stratospheric clouds, Geophys. Res. Lett., 17, 393, 1990.

Vuillard, C., Contribution a letude de l'etat vitreux et de la cristallisation des solutions aqueuses, Ann. de Chim., 2, 233, 1957.

Williams, L. R., and F. S. Long, Viscosity of supercooled sulfuric acid solutions, J. Phys. Chem. in press.

Worsnop. D. R., et al., Vapor pressure of solid hydrates of nitric acid, Science, 259, 71, 1993.

Zhang, R., et al., Physical chemistry of the $\mathrm{H}_{2} \mathrm{SO}_{4} / \mathrm{H}_{2} \mathrm{O}$ binary system at low temperatures: Stratospheric implications, J. Phys. Chem., 97. $7351,1993$.

A. Tabazadeh and O. B. Toon, NASA Ames Research Center, MS 245 4 (245-3 for O. B. Toon), Moffeu Field, CA 94035-1000.

P. Hamill, Department of Physics, San Jose State University, San Jose, CA, 94035..

(Received February 2, 1995; revised April 18, 1995;

accepted April 27, 1995) 